\title{
Lajikevalinta ja viljelytoimet avaimina apilanviljelyn menestykseen
}

\author{
Kaija Hakala $^{1)}$ ja Lauri Jauhiainen ${ }^{2)}$ \\ ${ }^{1)}$ MTT Kasvintuotannon tutkimus, 31600 Jokioinen, kaija.hakala@mtt.fi \\ ${ }^{2)}$ MTT Tietopalvelut, 31600 Jokioinen, lauri.jauhiainen@mtt.fi
}

Apilalajikkeet poikkeavat toisistaan sadontuotossa ja talvenkestävyydessä. Ne eroavat myös siinä, miten tehokkaasti ne pystyvät käyttämään hyväkseen suotuisia kasvuoloja. MTTn lajikekokeiden pohjalta tehtiin tilastollinen analyysi apilalajikkeiden eroista em. tekijöiden suhteen. Tutkituista lajikkeista tetraploidit Betty ja Ilte tuottivat suurimmat sadot. Lajikkeet Tepa, Varte, Jesper ja Björn tuottivat huonommat sadot kuin Betty ja Ilte keskinkertaisissa tai huonoissa oloissa, mutta hyvissä oloissa ne kirivät samalle satotasolle. Bjursele, Jokioinen, Hankkijan Venla ja Isomäki sen sijaan eivät yltäneet samoihin satomääriin hyvissäkään oloissa. Jos maatilalta löytyy lohkoja, jotka ovat erityisen hyvin apilanviljelyyn soveltuvia, niillä kannattaa viljellä hyvissä oloissa hyvän sadon tuottavia lajikkeita Betty, Ilte, Tepa, Varte, Jesper ja Björn. Betty- ja Ilte -lajikkeita kannattaisi myös käyttää nykyistä yleisemmin kaikentyyppisissä oloissa. Betty-lajikkeella oli lisäksi paras talvenkestävyys nyt tutkituista lajikkeista.

Apilalajikkeiden Jokioinen (paikallislajike, diploidi), Betty ja Ilte sadontuotto- ja kilpailukykyä luomuviljelyssä testattiin Jokioisilla peltokokeessa, jossa käsittelyinä olivat karjanlannalla lannoitetut (KL) ja väkilannoitteella lannoitetut (VL) lohkot. Apila kylvettiin joko yksin tai timotein, ruokonadan tai niiden seoksen kanssa. Ensimmäisenä satovuonna nurmi oli hyvin apilavaltaista. VL-aloilla apilavaltaisuus oli kuitenkin alusta asti pienempää kuin KL-aloilla. Heinän kasvu vahvistui tultaessa toiseen satovuoteen. Tämä oli erityisen selvää VL-ruuduilla, joilla liukoista typpeä oli väkilannoituksen myötä helposti saatavilla. Toisen satovuoden aikana apilan osuus sadosta alkoi vähentyä jo huolestuttavasti VL-aloilla. KL-aloilla oli apilaa vielä toisena satovuonna noin $50 \%$ tai enemmän.

Betty-apilan kokonaissato ja apilan osuus sadosta oli peltokokeen ensimmäisenä satovuonna pienempi kuin kahdella muulla testatulla lajikkeella, mutta toisena satovuonna se kilpaili heinän kanssa huomattavasti ansiokkaammin kuin muut kaksi lajiketta. Peltokokeen rinnalla tehdyn astiakokeen perusteella Betty-lajikkeen ajan myötä paraneva tulos voi olla seurausta biomassan allokoinnista juuriin suhteellisesti enemmän kuin muilla lajikkeilla varsinkin kasvun alkuvaiheessa. Tässä voi olla avain myös sen hyvään talvenkestävyyteen. Se, että KL-ruuduilla yleisestikin ottaen oli suurempi apilapitoisuus, saattaa johtua monista syistä. Ensinnäkin, kylvövuonna KL-ruutujen suojaviljakasvusto oli heikompaa, mikä johti apilan parempaan alkukasvuun pienemmästä kilpailusta ja suuremmasta valomäärästä johtuen. Heinän suurempaan osuuteen VL-ruuduilla on todennäköisesti vaikuttanut myös parempi typen saatavuus. Toisaalta apilan runsaampi alkukasvu KL-ruuduilla ensimmäisenä satovuonna on saattanut tukahduttaa niin heinän kuin rikkojenkin kasvua, ja tämän vaikutus voidaan nähdä vielä toisena satovuonnakin.

Apilanviljelyn menestyksen avaimet saattavatkin löytyä kasvin kasvustrategiasta ja siten lajikevalinnasta, mutta myös viljelytoimista jo kasvun alkuvaiheessa. Alkukasvun antamat edellytykset luovat pohjaa tulevien satovuosien menestykselle. Luomuviljelyssä apilalla näyttäisi olevan paremmat kasvuedellytykset kuin tavanomaisessa viljelyssä pienemmän heinien ja rikkakasvien kilpailun takia.

Tämä tutkimus on osa MMM:n luomuohjelman projektia "Puna-apila tehokkaasti luomumaidoksi".

Asiasanat: Puna-apila, heinä, lajikkeet, luomu, juuristo 


\section{Johdanto}

Puna-apilapitoinen nurmi säilyttää parhaan tuotantokykynsä kaksi satovuotta. Pidempi tuotantoaika olisi edullinen viljelijälle sekä työvoiman käytön että siemenkustannusten kannalta. Apilanurmen tuotantokyvyn laskuun kolmantena satovuonna on esitetty useita mahdollisia syitä. Yksi syy on kasvitautien, erityisesti Fusarium -sienten lisääntyminen. Talvituhot, mukaan lukien tautien (varsinkin apilamätä) aiheuttama tuho, ovat myös merkittävä apilan harventaja nurmessa. Käytännön apilanviljelyssä yksi apilan kasvua heikentävä tekijä voi olla apilakasvuston mekaaninen vioitus ja siitä seuraavat taudit (Leinonen 2005). Apila voi myös itse muuttaa kasvualustaansa esim. orgaanisen aineen ja typen määrän suhteen siten, ettei enää viihdy sillä. Puna-apilanurmen tehokkaan tuotannon keinoja on etsitty MMM:n luomuohjelman rahoittamassa tutkimuksessa 'Puna-apila tehokkaasti luomumaidoksi' v. 2003-2005. Tämän tutkimuksen tässä kirjoituksessa raportoitavassa osassa apilan tuotannon ongelmakohtia pyrittiin selvittämään kolmelta kannalta: 1. Selvitettiin tilastollisen mallin avulla, mikä apilalajike soveltuu parhainten viljelyyn eri tyyppisissä oloissa (Hakala \& al. 2004, Hakala \& Jauhiainen 2004), 2. Verrattiin luomutyypin (karjanlannalla lannoitetut ruudut, KL) ja tavanomaisesti viljellyn pellon (väkilannoitteella lannoitetut ruudut, VL) eroja puna-apilanurmen tuotantokyvyn kannalta, sekä 3. Selvitettiin astiakokeessa apilan ja heinän keskinäistä kilpailua sekä apilan kasvustrategiaa eri lajikkeilla (Hakala \& al. 2005).

\section{Aineisto ja menetelmät}

\section{Apilalajikkeiden olosuhdeherkkyys}

Nykyään käytössä olevien puna-apilalajikkeiden selviytymistä suotuisissa ja epäedullisissa oloissa testattiin MTT:n vuosina 1975-2003 keräämän lajikekoeaineiston avulla. Testattavina olivat lajikkeet Betty (tetraploidi), Bjursele, Björn, Hankkijan Venla, Ilte (tetraploidi), Isomäki, Jesper, Jokioinen, Tepa (tetraploidi) ja Varte (tetraploidi). Testaus tehtiin käyttäen toisen ja kolmannen satovuoden tuloksia.

\section{Peltokoe}

Peltokoe kylvettiin vuonna 2003 käyttäen ohraa suojaviljana. Koe jatkui vuosina 2004 ja 2005. Ruudut olivat $1,5 \mathrm{~m}$ leveitä ja $5 \mathrm{~m}$ pitkiä. Puolet ruuduista lannoitettiin karjanlannalla (KL, "siirtymävaiheen luomu") (30 tn/ha, liukoisen typen määrä 66-81 $\mathrm{kg} / \mathrm{ha})$, puolet väkilannoitteella (VL, "tavanomainen")(100 kg typpeä/satovuosi/ha). Molemmille ruututyypeille kylvettiin neljänä kerranteena kolme apilalajiketta: Jokioinen, Betty ja Ilte joko yksinään tai yhdessä timotein (Tuure), ruokonadan (Retu) tai niiden seoksen kanssa.

\section{Astiakoe}

Astiakokeeseen kylvettiin samat apila- ja heinälajikkeet kuin peltokokeeseen, mutta lisäksi uutena seosheinänä oli nurminata (Inkeri). Astioina käytettiin 11 litran vetoisia valkoisia muovisia altakasteluruukkuja, jotka täytettiin puhtaalla hiekalla (raekoko 0.2-0.7 mm). Kokeen alussa jokainen astia lannoitettiin seuraavasti (astiaa kohden): $0,81 \mathrm{~g}$ typpeä, $0,3 \mathrm{~g}$ fosforia, 1,5 $\mathrm{g}$ kaliumia, $0,3 \mathrm{~g}$ magnesiumia, $0,04 \mathrm{~g}$ natriumia, $0,010 \mathrm{~g}$ rautaa, sinkkiä ja mangaania, $0,005 \mathrm{~g}$ kuparia, $0,0045 \mathrm{~g}$ booria ja $0,001 \mathrm{~g}$ molybdeenia. Lisäksi hiekkaan sekoitettiin astiaa kohden $20 \mathrm{~g}$ magnesiumpitoista dolomiittikalkkia. Leikkuiden jälkeen astioihin lisättiin hivenaineita puolet kokeen alussa annetusta määrästä. Toisena kasvuvuonna annettiin lisäksi $1,5 \mathrm{~g}$ kaliumia, $0,3 \mathrm{~g}$ fosforia ja $0,017 \mathrm{~g}$ booria kasvukauden alussa ja kahden ensimmäisen leikkuun jälkeen. Typpeä ei lisätty astioihin alkulannoituksen jälkeen.

\section{Tulokset ja tulosten tarkastelu}

\section{Apilalajikkeiden olosuhdeherkkyys}

MTT:n lajikekokeiden pohjalta tehtiin tilastollinen analyysi, jossa testattiin apilalajikkeiden olosuhdeherkkyyttä. Analyysin perusteella tetraploidit Betty ja Ilte ovat satoisia sekä hyvissä että huonoissa oloissa. Jesper, Tepa ja Varte ovat keskinkertaisia huonoissa oloissa, mutta hyvissä oloissa Bettyn ja Ilten vertaisia. Muut testatut lajikkeet ovat keskinkertaisia sekä hyvissä että huonoissa oloissa. 
Hankkijan Venla ja Jokioinen ovat muita huonompia satotasoltaan (Hakala \& al. 2004). Yhtenä syynä lajike Bettyn menestymiselle voi olla muita lajikkeita parempi talvenkestävyys. Se ei kärsi huonoissakaan oloissa talvituhoista yhtä paljon kuin muut lajikkeet (Hakala \& Jauhiainen 2004).

Olisi hyvä, jos viljelijä voisi valita hyviin pelto-oloihin niillä parhaan sadon tuottavia lajikkeita eikä joutuisi tyytymään keskinkertaisiin lajikkeisiin, kuten nykyään yleinen Bjursele-lajike, jotka kyllä saattavat olla viljelyvarmoja, mutta joilla ei koskaan saavuteta huipputuloksia.

\section{Apila-heinäyhdistelmien biomassan kertyminen ja jakautuminen eri kasvinosiin}

Astiakokeessa tutkittiin eri apilalajikkeiden ja heinä-apilaseosten biomassan jakautumista toisaalta heinän ja apilan, toisaalta korjattavan osan ja juuriston välillä. Kokeen alussa suurin osa biomassasta kertyi heinäosapuoleen, joka kasvoi ilmeisesti lannoitetypen turvin. Jo toisesta leikkuusta lähtien apila alkoi kuitenkin vallata tilaa heinältä. Kokeen kuluessa heinän kasvu tyrehtyi olemattomiin, luultavasti typen puutteen takia (Hakala \& al. 2005). Puna-apilalajikkeista Ilte tuotti eniten korjattavaa biomassaa kokeen alusta lähtien. Jokioinen-lajike oli toiseksi paras sadontuottaja kokeen ensimmäisenä vuonna. Lajike Betty oli ensimmäisenä kasvuvuonna huonompi sadontuottaja kuin kaksi muuta lajiketta, ja se oli myös huonompi kilpailija heinien kanssa. Tässä suhteessa astiakokeen havainnot täsmäävätkin peltokokeen kanssa. Ensimmäisen kasvuvuoden syksyllä havaittiin, että vaikka Bettyn maanpäällinen osa oli pienempi kuin muilla lajikkeilla, sen juuristo oli erityisen hyvin kehittynyt muuhun biomassaan nähden. Vielä kahdenkin vuoden kasvun jälkeen Betty oli ylivoimainen, kun lajikkeita verrattiin suhteelliselta juuristomassaltaan (Kuva 1). Toisena kasvuvuonna Betty ohitti Jokioinen-lajikkeen myös sadontuotossa. Lajiketestauksessa saatu tulos Betty-lajikkeen hyvästä talvenkestävyydestä saattaa osaltaan johtua sen suhteellisesti suuresta juurimassasta. Juuriin varastoituneiden sokerien ja suuren juurimäärän turvin apila voi kestää paremmin talvituhoja. Kasvukautena tällainen apila saavuttaa paremmin ravinteet ja vesivarat ja voi aloittaa kasvun nopeammin, jolloin se myös pärjää paremmin kilpailussa.

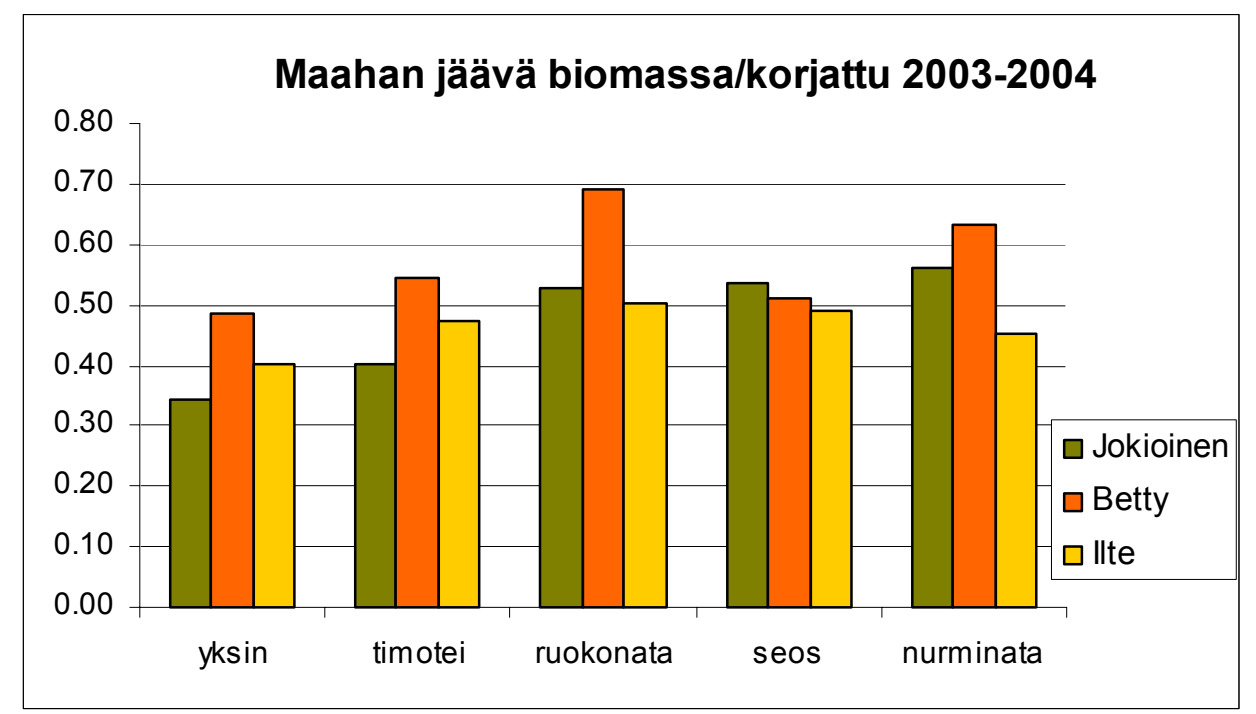

Kuva 1. Puna-apilalajikkeiden Jokioinen, Betty ja Ilte maahan jäävän biomassan suhde

korjattuun biomassaan kahden vuoden kasvatuksen jälkeen. Kyseessä on koko astian maanpäällinen biomassa ja juuristomassa. Mukana ovat sekä apila että heinä, kun apila on kylvetty yhdessä heinäosapuolen kanssa (timotei, ruokonata, timotein ja ruokonadanseos tai nurminata). "yksin": apila ilman heinäosapuolta

\footnotetext{
Apila-heinäyhdistelmien menestyminen luomu- ja tavanomaisessa viljelyssä

Peltokokeessa ensimmäinen satovuosi oli apilavaltainen, varsinkin luomuviljelyssä (KL-ruuduilla), joilla apilaa oli 80-90\% koko sadosta. Tavanomaisessa viljelyssä (VL-ruuduilla) apilan osuus jäi 60-70\%:iin, jos mukana oli seosheinä. Yksinään kylvettynä apila valtasi suurimman osan (n. 80\%) kasvualasta myös VL-
} 
ruuduilla. Vuonna 2004 apilalajikkeet eivät eronneet sadontuotoltaan KL-ruuduilla, mutta VL-ruuduilla Betty-apilan sato oli heikompi kuin muiden lajikkeiden (Kuva 2A). Vuonna 2005 kaikkien apilalajikkeiden sadot olivat laskeneet, laskun ollessa suurinta VL-ruuduilla (Kuva 2B). Eniten oli laskenut Jokioinen-lajikkeen sato molemmilla lannoitustyypeillä. Betty-lajikkeen sadon lasku oli suhteellisesti pienempää kuin muiden lajikkeiden.

Apilasatojen laskiessa heinä alkoi vallata alaa sekä KL- että VL-ruuduilla (Kuva 2B). VL-ruuduilla apilan osuus kokonaissadosta laski toisena satovuonna 40-20\% tietämiin, kun KL-ruuduilla apilan osuus oli vielä noin puolet tai enemmän koko sadosta. Sen sijaan apilanurmen kokonaissadot olivat samantasoiset VL- ja KL-ruuduilla ensimmäisenä satovuonna (Kuva 2A). Toisena satovuonna kokonaissadot laskivat KL-ruuduilla, mutta nousivat VL-ruuduilla, joilla heinäsadon kasvu kompensoi apilasadon vähenemistä (Kuva 2B).

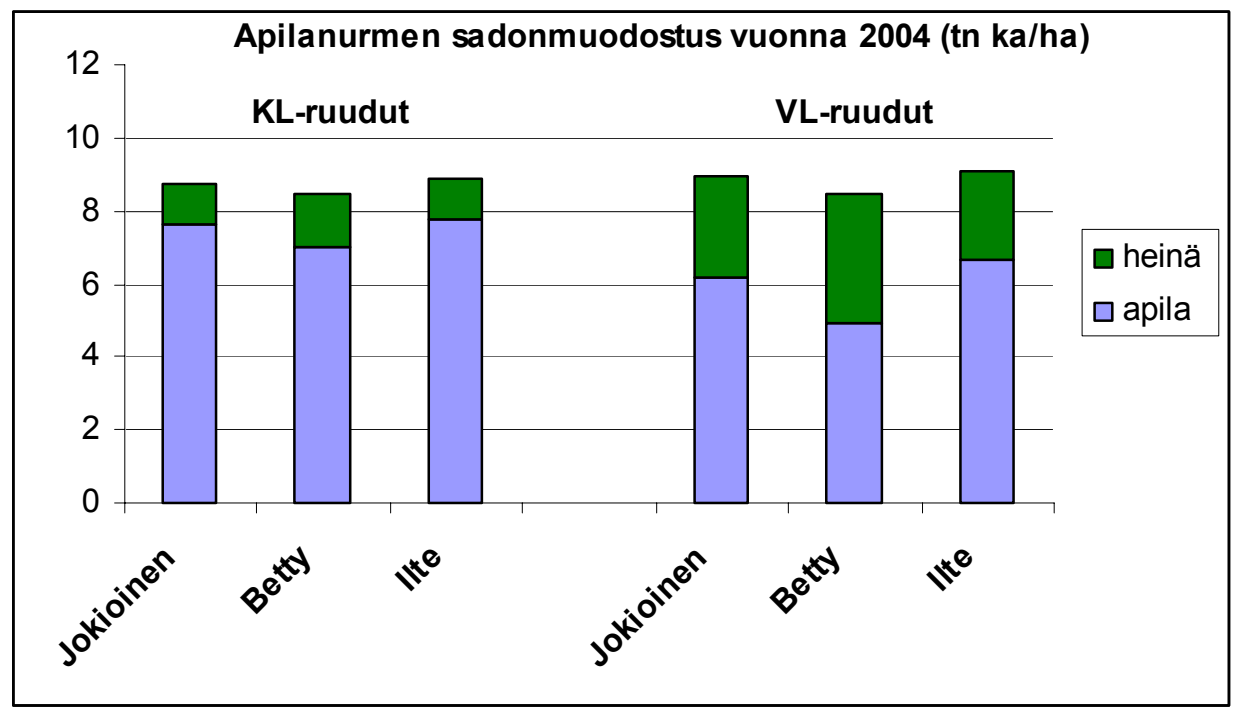

A

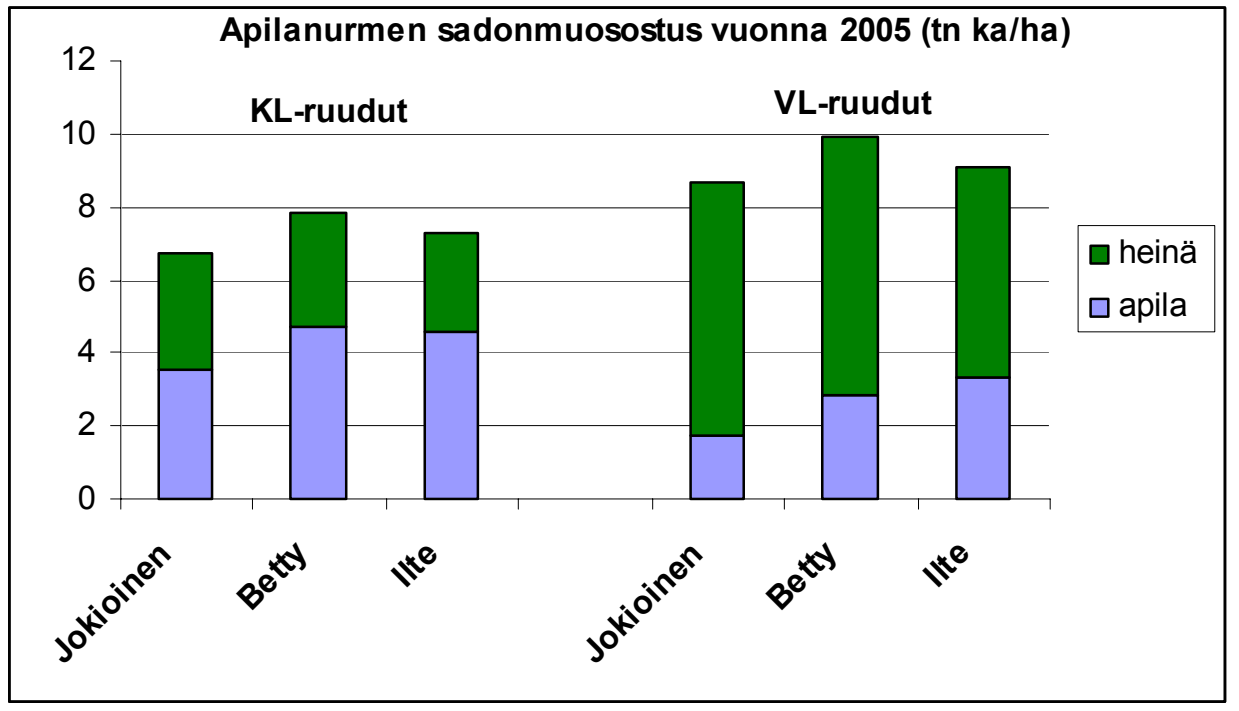

B

Kuva 2. Apilanurmen sadonmuodostus A vuonna 2004 (1. satovuosi) ja B vuonna 2005 (2. satovuosi). Kahden leikkuukerran kokonaissato, tn kuiva-ainetta hehtaaria kohti. Apila on puhdasta puna-apilaa, heinä-osuudessa on mukana myös rikat (n. 10\% kokonaissadosta). Tulos on kaikkien 
apila-heinäseosten keskiarvo (apila ja timotei, apila ja ruokonata sekä apila ja timotein ja ruokonadan seos).

Tulokset osoittavat, että väkilannoitteella maltillisestikin lannoitettaessa apila väistyy nopeammin heinäosapuolen tieltä kuin luomuviljelyssä. Luomuviljelyssä apilalla on siten paremmat menestymisen edellytykset kuin tavanomaisessa viljelyssä. Puna-apilalajikkeet eroavat sadontuotoltaan ja säilyvyydeltään nurmessa. Ilte-lajike oli tässä kokeessa satoisin, mutta Betty-lajike ei jäänyt paljon jälkeen ja saattaa kestää talven tautihyökkäykset paremmin kuin Ilte. Samoin kuin astiakokeessa, Betty-apila oli peltokokeessakin pitkällä tähtäyksellä kestävämpi ja parempi kilpailija heinän kanssa kuin muut tässä testatut apilalajikkeet. Kokeen kolmas satovuosi vuonna 2006 tulee olemaan mielenkiintoinen apilan säilymisen kannalta.

\section{Johtopäätökset}

Puna-apilalajikkeet poikkeavat toisistaan siinä, miten hyvin ne pystyvät hyödyntämään hyviä kasvuoloja. Lajikkeet Betty ja Ilte ovat satoisimpia kaikissa oloissa, ja Betty on myös erittäin talvenkestävä. Hyvillä lohkoilla kannattaa viljellä paitsi näitä erinomaisen sadon tuottavia lajikkeita, myös muita lajikkeita, jotka saavuttavat huippusatoja hyvissä oloissa, vaikka huonoissa oloissa ovat keskinkertaisia. Viljelijän ongelmana onkin kylvösiemenen saatavuus. Betty-lajikkeen hyvän talvenkestävyyden ja sadontuoton salaisuus saattaa olla sen juuriston suhteellisen suuri osuus biomassasta, varsinkin alkukasvun aikana. Luomuviljely näyttää sopivan erityisen hyvin puna-apilan viljelylle, koska apilan osuus laski hitaammin pellolla, joka oli lannoitettu naudan kuivikelannalla (30 tn/ha eli 66-81 kg liukoista typpeä/ha) kokeen alussa kuin pellolla, joka sai $100 \mathrm{~kg}$ väkilannoitetyppeä/ha/vuosi.

\section{Kirjallisuus}

Hakala, K., Nikunen, H.-M. \& Jauhiainen, L. 2004. Puna-apilalajikkeen valinta varmistaa tehokasta nurmituotantoa. In: Päivitä tietämyksesi Luomusta : Luomuseminaari Mikkelissä 28.7.2004. Mikkeli: p. $15-16$.

Hakala, K. \& Jauhiainen, L. 2004. Hyvä apilalajike kestää talvea. Koetoiminta ja käytäntö 61, 4 (13.12.2004): 3 .

Hakala, K., Nikunen, H.-M. \& Jauhiainen, L. 2005. Biomass production of different grass/red clover mixtures. In: B.E. Frankow-Lindberg, R.P. Collins, A. Lüscher, M.T. Sébastia, Á. Helgadóttir (eds.) Adaptation and Management of Forage Legumes - Strategies for Improved Reliability in Mixed Swards : Proceedings of the 1st COST 852 workshop held in Ystad, Sweden 20-22 September 2004. Uppsala: SLU. p. 183-186.

Leinonen, P. 2005. Apilan taudit: kestääkö moottori. Kasvinsuojelulehti 3/2005: 72-73. 